\title{
Clean Development Mechanism Afforestation and Reforestation Projects: Implications for Local Agriculture
}

\author{
Arthur G. Green and Jon D. Unruh \\ McGill University
}

\begin{abstract}
:
The potential of Clean Development Mechanism Afforestation \& Reforestation (CDM A/R) projects to make contributions to climate change mitigation and sustainable development is widely-recognized. Yet, problems with the design and implementation of $C D M A / R$ projects have limited analyses of project outcomes. In fact, of the nearly 1400 registered CDM projects in early January 2009 there was only one A/ $R$ project. Yet, as of May 2010, the number of registered CDM A/R projects had rapidly grown to 14 with 41 more $C D M A / R$ projects in the pipeline. This rapid increase in $A / R$ activities may provide some early indications of whether $C D M A / R$ projects are successfully meeting their potential to contribute to sustainable development goals. This review specifically examines literature that documents the positive and negative impacts of $C D M A / R$ projects on local agriculture. It finds that while half of the current $C D M$ $A / R$ projects are credited with generating carbon offsets from 2007 or earlier, there is little published evidence of their specific impacts on local agriculture or sustainable development. This review recommends that future research focus on (1) developing field surveys with criteria and indicators that evaluate the performance of individual CDM A/R projects in meeting stipulated outcomes, (2) increasing critical scrutiny of CDM A/R project validation documentation and procedures, and (3) developing criteria and indicators to analyze the impacts of all CDM A/R projects on broad issues (such as tenure security and institutional capacity) and specific demographic groups, geographic regions, or livelihoods.
\end{abstract}

\section{Keywords:}

CDM, afforestation, reforestation, agriculture.

\section{Introduction}

The focus of this review is on the impacts of registered Clean Development Mechanism Afforestation \& Reforestation (CDM A/R) projects on local agriculture. The 1997 Kyoto Protocol set binding targets for greenhouse gas (GHG) emission reductions on Annex I countries (1). ${ }^{1}$ These countries agreed to reduce emissions through national measures and three flexible, market-based mechanisms: Emissions Trading, Joint Implementation (JI), and the Clean Development Mechanism (CDM). The CDM has two stated aims: to assist industrialized countries to meet their emission reduction targets by purchasing or generating carbon offsets and to support sustainable development in host countries (see Kyoto Protocol Article 12.2) (2)..$^{2}$ In other words, the CDM allows industrialized countries to meet a portion of their emission reduction targets by either purchasing carbon offsets

\footnotetext{
1 The Kyoto Protocol's Annex I countries are often called "industrialized" countries, while non-Annex I countries are often called "developing" countries.

2 For more information on the CDM see Article 12 of the Kyoto Protocol and refer to documentation on the CDM on the UNFCCC CDM website (http://cdm.unfccc.int/about/index.html).
} 
that were generated through CDM registered projects or earning carbon offsets by creating or investing in CDM registered projects. While the CDM recognizes several activities that create carbon offsets, all CDM project activities must take place in and contribute to the sustainable development goals of non-Annex I (host) countries. ${ }^{3}$ This geographic restriction and the focus on sustainable development differentiate CDM activities from $\mathrm{Jl}$ and other carbon market activities that produce or accept different types of carbon offsets. ${ }^{4}$ Carbon offsets generated through all CDM project activities are known as Certified Emission Reductions (CERs) and are equivalent to one metric ton of carbon dioxide. 5 Within the CDM, afforestation and reforestation are the only Land Use, Land-Use Change and Forestry (LULUCF) activities (as designated in Article 3.3 of the Kyoto Protocol) recognized to create CERs (3). ${ }^{6}$ However, a post-2012 climate agreement is likely to change the CDM, broaden the activities recognized in the LULUCF classification, or add new classifications that include activities like agriculture, forestry, or other land uses (AFOLU) and reduced emissions from deforestation and forest degradation (REDD+) (3-5).

The potential of CDM A/R projects to sequester carbon and to make contributions to sustainable development is widely-recognized (6-13). Yet, there are diverging opinions regarding whether such projects can be implemented throughout the world (14), how

3 "Developing" countries, also known as host countries, argued that 'sustainable development' had to be nationally defined because an international definition would infringe on sovereignty. As a result, host countries' Designated National Authorities became responsible for defining sustainable development and evaluating whether CDM projects contributed to sustainable development (15).

4 For example, Joint Implementation (JI) projects produce Emission Reduction Units (ERUs), non-certified projects produce a number of different Voluntary Emissions Reductions (VERs), and some markets accept offsets that are slightly different from or equivalent to CERs and ERUs (like the Voluntary Carbon Standard or the EU Emissions Trading Scheme's use of EU Allowance Unit (EUAs)).

${ }^{5}$ Among CDM projects, CDM A/R projects are unique in that they produce modified forms of CERs. CDM $A / R$ projects produce temporary certified emission reductions (tCERs) and long term certified emission reductions (ICERs). The difference between a tCER and a LCER being that a tCER expires at the end of the commitment period in which it was issued and a ICER expires at the end of the crediting period of the project. Depending on the project, a ICER may be valid for up to 60 years.

${ }^{6}$ The Kyoto Protocol defines afforestation as "the direct human-induced conversion of land that has not been forested for a period of at least 50 years to forested land through planting, seeding and/or the human-induced promotion of natural seed sources" and reforestation is defined as "the direct humaninduced conversion of non-forested land to forested land through planting, seeding and/or the humaninduced promotion of natural seed sources, on land that was forested but that has been converted to nonforested land... on those lands that did not contain forest on 31 December 1989" (see Decision 16/CMP.1, Annex, paragraph 1(b-c)) (52). Forest is defined as " a minimum area of land of 0.05-1.0 hectare with tree crown cover of more than 10-30 per cent with trees with the potential to reach a minimum height of 2-5 metres at maturity in situ" (see Decision 16/CMP.1, Annex, paragraph 1(a)) (52). Of the 14 currently registered CDM A/R projects, 13 are considered reforestation projects and only the Small Scale Cooperative Afforestation CDM Pilot Project Activity on Private Lands Affected by Shifting Sand Dunes in Sirsa, Haryana project is considered an afforestation project. 
'sustainable development' can and should be defined $(10,15)$, whether market mechanisms actually contribute to carbon mitigation (16-18), and whether benefits from carbon forestry projects in general and CDM A/R projects in particular are equitably distributed $(16,19-22)$. Indeed, problems with the design, cost efficiencies, and implementation of potential CDM A/R projects have effectively limited the number of afforestation and reforestation projects certified by the CDM (5). For example, of the nearly 1400 registered CDM projects in early January 2009 there was only one A/R project - the Facilitating Reforestation for Guangxi Watershed Management in Pearl River Basin project in China. However, by May 2010, the number of registered CDM A/R projects had rapidly grown to 14 (out of 2171 total registered CDM projects) and there were 41 more CDM A/R projects requesting registration, under review, or at validation. It is estimated that, if all these 41 applicants are registered, these $55 \mathrm{~A} / \mathrm{R}$ projects will produce $15,780(0.6 \%)$ of the $2,854,824$ CERs expected to be generated by all CDM projects by 2012 (23). Taken alone, the 14 currently registered CDM A/R projects should capture some 8084 kilotons of carbon dioxide by 2020 (23).

While the limited but quantifiable carbon sequestration of CDM A/R projects can be estimated, there is less data and less understanding of CDM A/R activities' socioeconomic impacts $(24,25)$. As a result, analyses of these projects' impacts on sustainable development have been limited to hypothetical scenarios or to examinations of how prototype projects have functioned on the ground. Indeed, many articles that discuss the potential socioeconomic impacts of CDM A/R projects draw conclusions from case studies of voluntary forest carbon projects' and forest conservation projects' impacts on sustainable development $(5,10,13,19,24-27)$. Yet, CDM A/R projects have a number of procedural requirements and unique institutional arrangements that might produce very different results from non-CDM projects - especially since avoided deforestation, forest conservation, and soil carbon activities are not presently recognized as CDM carbon offset strategies. In many ways, studies that focus on afforestation and reforestation projects designed (through funds like the Prototype Carbon Fund or BioCarbon Fund) in anticipation of CDM registration have more meaningful conclusions as these projects make explicit connections to CDM criteria and procedures and were designed with the hopes that they would eventually produce CERs $(24,28,29)$. These studies document local benefits like short-term employment generation, income and knowledge generation, capacity-building, and property registration, but also point to a consistent lack of follow through on social objectives and social programs stipulated in project designs $(22,24)$.

The recent increase of CDM A/R registered projects provides an opportunity to reconsider CDM A/R registered projects' broad socioeconomic impacts and specific impacts on local agriculture. While looking to recently registered projects for evidence of impacts may seem premature, several of the projects registered between January 2009 and May 2010 were credited with carbon offsets that go back 3-8 years before their 
registration dates (as early as 2001) (see table 1) (30). ${ }^{7}$ Considering the long term crediting period for many of these new projects and the long term experience with the 2006-registered Guangxi Watershed project, a review of studies that examine the actual biophysical and socioeconomic impacts of these projects may provide new insights or indicate research gaps.

Rather than focus broadly on sustainable development, this review focuses on literature that analyzes how CDM A/R projects positively or negatively impact local agriculture. While 'sustainable development' is often mentioned as both an analytical tool and development goal in literature on CDM projects (10), there are ongoing concerns about and political challenges over how sustainable development is defined and pursued within the context of $\operatorname{CDM}(10,15,31) .8$ This review's focus on local agriculture may not capture the broad context that sustainable development $(28,32)$, the livelihoods approach (33), or a focus on access, capacities, or rights (34) would portray, but it does contribute to these broader efforts by summarizing literature that examines impacts on a specific livelihood strategy and demographic group that must be considered for realistic sustainable, rural development. The following sections outline this literature review's methods, provide a brief background on current CDM A/R projects, and provide a framework for understanding literature that examines the impacts of CDM $A / R$ projects on local agriculture. The review concludes with recommendations for future research avenues.

\section{Review Method}

As mentioned above, the multiplication of registered CDM A/R projects is a relatively new phenomenon. As a result, there are few published, peer-reviewed academic articles that measure the actual socioeconomic or biophysical impacts of CDM A/R projects. This scarcity of peer-reviewed academic publications on the actual impacts of specific CDM $A / R$ projects required this review to include additional investigation into grey literature ${ }^{9}$ and CDM A/R project documentation. The literature covered in this review was obtained using combinations of the keywords "clean development mechanism," "CDM," "agriculture," and variations of the names of the 14 registered CDR A/M projects in the following search engines: ISI Web of Knowledge, Scopus, Google Scholar, and Google. ${ }^{10}$ Additional materials were also obtained from the United Nations Framework Convention

\footnotetext{
7 These four projects are the Reforestation of severely degraded landmass in Khammam District of Andra Pradesh India under ITC Social Forestry Project, the Forestry Project for the Chinchiná River Basin in Columbia, The International Small Group and Tree Planting Program (TIST) in India, and the Assisted Natural Regeneration of Degraded Lands in Albani.

8 Olsen (10) offers an overview of CDM projects and sustainable development.

9 We use "grey literature" to signify information produced in electronic and print formats by all levels of government, non-governmental organizations, and businesses.

10 These web address for these search engines are ISI Web of Knowledge (www.isiknowledge.com), Scopus (www.scopus.com), Google Scholar (www.scholar.google.com), and Google (www.google.com).
} 
on Climate Change (UNFCC), the United Nations Environmental Programme (UNEP) Risoe CDM/JI Pipeline Analysis and Database, and the World Bank Carbon Finance Unit. ${ }^{11}$ A snowball sampling strategy (35) was used on the bibliographic references of academic articles and grey literature to extensively cover additional materials. In order to include the crediting period start dates of all currently registered CDM A/R projects, this review focused on materials published between January 2000 and May 2010.

\section{Social Challenges and Social Impacts in Current CDM A/R Projects}

The long delay in CDM A/R growth reflects the unique challenges of establishing CDM A/ $R$ projects in comparison with other $\operatorname{CDM}$ projects $(3,5,36)$. Many of the challenges of implementing CDM A/R projects are the same as challenges faced by non-CDM forestry projects in developing countries (14). These challenges include competing property claims, undocumented and insecure property rights, poor governance and lack of local institutional capacity, human migration, tree tenure issues, lack of secure or reliable markets and suitable pricing policies, lack of appropriate technologies, long rotation periods, competition with more profitable land uses, and the problem of scaling up or scaling down successful activities $(6,14,37)$. Yet, Kyoto compliant, CDM A/R projects face additional challenges beyond those faced by normal forestry projects. These additional challenges include the financial hurdles unique to CDM and difficulties with CDM's validation, registration, and verification processes. Not only do these processes require overcoming concerns about additionality, permanence, and leakage, but they also impose significant costs in that they require locating the technical capacity to meet project needs, establish biophysical and socioeconomic baseline data, and guarantee monitoring and management $(13,36)$.

The CDM contains rigorous procedures that must be followed by projects that wish to be and that are CDM registered $(2,38)$. There are several 'methodologies' recognized by the CDM as approved ways to establish projects that sequester carbon through afforestation and reforestation. These methodologies define how a project is classified by the CDM and layout procedures for applications for registration. Among other things, these methodologies define formulas for establishing baseline estimations of vegetation, project additionality, and leakage; require definition of policy mechanisms for project implementation; and determine whether environmental impact assessments are necessary, legal concerns remain, and social challenges or impacts might undermine the project. Within these methodologies, social impact assessments are often included as part of environmental impact assessments. Usually, clear plans for overcoming and mitigating potential socioeconomic challenges and impacts are necessary as part of the social impact assessment or upon validator requests for clarification. For example, plans

\footnotetext{
11 The search reflects data from the UNFCCC CDM (http://cdm.unfccc.int/), UNEP Risoe CDM/JI Pipeline Analysis and Database (http://www.cdmpipeline.org/), and World Bank Carbon Finance Unit (http:// wbcarbonfinance.org) website current as of 10 May 2010.
} 
must be included for issues like community resettlement, changes to legal zoning, property rights disputes, or changes in current land use patterns.

In CDM project documentation, data on social challenges and impacts gathered as part of environmental impact assessments is usually found in sections on sustainable development. Designated National Authorities (DNAs) in host countries are ultimately responsible for the definition of sustainable development and enforcement of compliance with sustainable development goals (15). DNAs ultimately approve and verify socio-economic impacts. However, host countries sometimes have lenient definitions of sustainable development, problems with institutional coordination, and less stringent requirements for social impact assessments $(10,28,39)$. As a result, social impact assessments and project sustainability documentation tend to focus more on economic sustainability (job creation) and plans to overcome social challenges to implementation rather than the creation of beneficial socio-economic impacts or possible negative socio-economic impacts. ${ }^{12}$ This results in less extensive identification of potential socioeconomic impacts than needed in many cases (17) and has left many open questions in regard to inequitable benefit distribution $(19,27)$. In addition to the above problems, follow-through implementation of social programs stipulated in project designs seems to be a recurring problem $(22,24,29)$. Thus, while CDM methodologies and required documentation are not fool-proof indications of projet contributions to sustainable development, these methodologies and documentation provide indications of what projects plan to do, what factors have been considered, and what results are expected.

Table 1 outlines some basic details about each of the 14, currently registered CDM A/R projects. Six of the 14 registered CDM A/R projects are classified as AR-AMS0001 (smallscale ${ }^{13}$ afforestation and reforestation project activities under the clean development mechanism implemented on grasslands or croplands), two as AR-AM0001 (reforestation of degraded land), one as AR-AM0002 (restoration of degraded lands through afforestation/reforestation), four as AR-AM0003 (afforestation and reforestation of degraded land through tree planting, assisted natural regeneration and control of animal

\footnotetext{
12 For example, the social impact section of the 2001 environmental assessment for the Prototype Carbon Fund and Plantar project in Brazil consists of five sentences that state that the project will consult with communities, will create more local jobs that may help undermine charcoal production activities that use child labor, and will not cause involuntary resettlement. The 2002 World Bank project appraisal marginally improves on this statement by indicating that the project will maintain good labor conditions and will create health benefits by reducing local air pollution through modernizing 'carbonization processes'. Yet, Boyd et al. (24) find that beyond creating jobs, complying with child labor laws, and creating a modest environmental education program, the Plantar project missed many opportunities to include local communities and create social benefits - the project "fell short of contributing to agricultural extension and capacity building of small land owners" (pg.425).

13 Small-scale CDM A/R projects are those that sequester less than 16,000 kilotons of carbon dioxide on an annual basis (38).
} 
grazing), and one as AR-AM0004 (Reforestation or afforestation of land currently under agricultural use). While it would seem that projects that are AR-AMOOO4 or ARAMS0001 are most relevant to understanding CDR A/R project impacts on local agriculture, the reality is that the legal structure of many countries may deny existing local tenure systems. So, projects that are compliant with national legal codes or classified under any methodology may still have negative (or positive) impacts on property rights and local agricultural practices.

\section{Impacts of CDM A/R Projects on Local Agriculture}

The potential and actual impacts of CDM projects on local livelihoods and sustainable development are noted in project design documentation (PDD) and in several studies some of which directly address $A / R$ projects $(6,10,13,16,20-22,24,27-29,40-48)$. The potential positive impacts of CDM A/R projects on local agriculture include:

1. increased income applied to farm investments (for example, CER payments, offfarm employment, or non-timber forest products) $(13,24,41,45,49)$,

2. soil improvement (such as erosion control, increased fertility, and increased moisture retention) $(13,27)$,

3. hydrology improvement (increases in the quantity and quality of available water, reduction in runoff, and decreases in soil water content) (42),

4. infrastructural investment (that facilitate access to markets, information, or agricultural inputs) $(13,41,46)$,

5. agriculturally relevant technology transfer (such as new equipment or inputs) $(13,24)$,

6. opportunities for agricultural training (such as agricultural extension) $(13,41,49)$,

7. increased local institutional capacity (regarding transparency, accountability, and access and representation in both local government and agricultural cooperatives) $(13,41)$,

8. legal recognition of property rights $(24,29,41)$, and

9. improvement in risk management (such as increases in crop diversification, decreases in natural hazards, increases in social capital capacities) $(22,41)$.

The above studies also indicate risks of negative impacts that CDM A/R projects can have on local agriculture - risks that are often simultaneously limiting factors of project implementation:

1. threats to or insecurity of property rights (such as threats to agricultural land or investments that are privately or communally owned) $(6,14,22,26,29)$,

2. destruction of existing vegetation resources (like wild foods or seasonal grazing lands) $(13,44,49)$,

3. loss of right to access forests during periods of food insecurity or shortage (46), 
4. increased threat of water damage or decrease in water availability (improvements in hydrological systems may cause changes in the physical landscape that benefit some while threatening others) (42),

5. involuntary resettlement (13),

6. loss of agricultural employment and agricultural crops due to labor move to higher income forestry sector jobs $(41,49)$, and

7. elite capture of benefits or inequitable distribution of economic and other benefits (which may undermine existing institutions, cause increased livelihood risk, or expose some communities to hazard) $(16,19,20,27,29,48)$.

There is very little academic or grey literature that details actual impacts of registered CDM A/R projects. The CDM A/R PDD (50) and most of the existing academic literature deal with potential impacts of CDM A/R projects or draw conclusions from $A / R$ projects not registered with the CDM. For example, as part of projects' sustainable development contributions, the PDD for all 14 of the registered CDM A/R projects include increased income through off-farm employment and increased income from payment for CERs or land access. Indeed, several studies have documented increased income from CDM A/R projects $(29,49)$, yet there are no current studies that investigate agricultural investment as a result of increased income from CDM A/R projects. Serious concerns over elite capture and the equitable distribution of benefits is a recurring theme throughout the academic literature $(16,19,20,27,29,48)$. Yet, there are no studies that document how inequitable distributions of registered CDM A/R project benefits negatively impact local agriculture. The PDD for all projects also mention the socio-economic benefits of soil and hydrology improvement. While there are typically improvements in erosion control, soil fertility, and moisture retention where forestry projects follow best practices (27, 51 ), there are currently no published studies that document increases in agricultural production as a result of soil improvement caused by registered CDM A/R project activities. In work linked to the CDM A/R project Carbon Sequestration through Reforestation in the Bolivian Tropics by Smallholders of "The Federación de Comunidades Agropecuarias de Rurrenabaque (FECAR)", Trabucco et al. (42) find that CDM A/R impacts on runoff reduction and soil water content depend on a number of context dependent variables. However, the impacts of CDM A/R caused hydrological change on agricultural production are not documented in this or any other published work.

In table 2, literature that documents registered CDM A/R projects' impacts on local agriculture is organized according to each of the 14 projects. While many of these projects may have negative and positive impacts not shown in the table, the table only includes impacts documented in published literature. Additional impacts require further investigation before they might be included in this table. Table 2 shows that while institutional capacity building, legal recognition of property rights, and carbon offset payments or employment income that go towards agricultural investment are common features of projects' early implementation, there is little evidence of the other potential contributions that these projects are assumed to make to local agriculture. At the same 
time, documented risks to communal tenure and backlash against inequitable benefit distribution weigh against these actual and potential positive impacts. Considering the negative impacts in table 2 , it is not clear that local agriculture has benefitted from CDM A/R projects.

As also indicated in table 2, there are frequently no documented outcomes that refer specifically to local agriculture. Beyond employment provision, payment for ecosystem services, and anticipated improvements to soil and water, PDD and validation reports often report vague, potential contributions to sustainable development and list no potential negative impacts on local agriculture - in fact, no negative socio-economic impacts at all. The lack of published work documenting socio-economic and biophysical impacts on local agriculture is troubling, especially considering that seven of the 14 current CDM A/R projects have been approved to issue credits generated between 2001-2007 - dates well before their actual registration. While host country definitions and verification of sustainable development are often considered adequate, there is clearly a need to document a broad array of actual impacts and to go beyond analysis of policy aims and acceptance of host country verification of sustainable development. This lack of published work provides an opportunity to examine both the specific impacts of individual projects and the general impacts of all projects on broad issues (such as tenure security, institutional capacity, natural assets, or infrastructure) and specific demographic groups, geographic locations, or livelihoods.

\section{Conclusion}

As the number of registered CDM A/R projects is now quickly growing and the number of LULUCF projects may increase dramatically with a post-2012 climate agreement, there is an urgent need to understand the actual socio-economic and biophysical impacts of LULUCF projects. Since afforestation and reforestation are the only activities currently recognized within the LULUCF classification, registered CDM A/R projects should be critically evaluated for their actual returns to and impacts on local livelihoods. Are they living up to their potential? If not, what changes need to be made in the CDM framework to produce sustainable socioeconomic results when additional activities like avoided deforestation or agricultural and soil carbon sinks may create CERs?

This review finds that data and analyses of the impacts of registered CDM A/R projects on local agriculture are often entirely missing from PDD, grey literature, and academic literature. Even as many recently registered projects are credited with CERs dating back as far as 2001, there is little available data on projects' socio-economic impacts. The validation and verification processes for projects and the credits they produce currently rely heavily on Designated National Authorities' approval of project compliance with host country definitions of sustainability. Yet, it appears that in some cases host country definitions of sustainability and host country institutional arrangements allow project implementers to give little attention to gathering socio-economic impact data beyond employment figures and payments from credit markets. The current emphasis on 
sustainable development in CDM A/R projects seems to be primarily on the provision of temporary forestry employment. Yet, attention to indicators of personal health, agricultural investment, and food security are also some of the criteria necessary for considering a larger view of socio-economic sustainability and durable contributions to rural livelihoods. While definitions of sustainability might remain the priority of host countries, a broader range of socio-economic impacts (more than local employment and carbon credit payments) need to be clearly linked to project validation and verification.

In order to fill this information gap and to understand actual impacts of CDM A/R activities, we recommend the following research priorities. First, more critical attention should focus on assumptions within the CDM validation process and on the procedures used to design and implement social and environmental impacts assessments. These assumptions and procedures may underestimate negative socio-economic impacts and result in missed opportunities to support local agriculture. Second, future research must engage with field surveys in registered project areas. These surveys should evaluate the performance of registered CDM A/R projects in meeting stipulated socio-economic outcomes and what constraints might be hindering those outcomes. This data should be made public as raw data and in published analyses. Third, studies should move beyond national definitions of sustainable development to develop or adopt clearly defined criteria and indicators that focus on a broad array of tangible impacts on access, rights, capacities, and assets. This emphasis on developing a framework of criteria and indicators for analysis of the impacts on broad issues (such as tenure security and institutional capacity) and specific demographic groups, geographic regions, or livelihoods would allow individual studies to be aggregated and may reveal patterns in project activities and outcomes. Fourth, these criteria and indicators should be used to collect data on socioeconomic baselines before project validation. These baselines should be included in PDD so that the impacts of projects can be compared to a historical baseline. Without fulfilling the above priorities, studies that evaluate whether CDM A/R projects individually or as a group are living up to their potential to contribute to local agriculture, sustainable development, or rural livelihoods will reflect only partial understandings of particular projects and not give insight into the broader challenges, failures, and successes of CDM A/R projects.

\section{References}

1. UNFCCC. Clean Development Mechanism, 2008 In Brief. Bonn, Germany: UNFCCC; 2008.

2. UNFCCC. Kyoto Protocol to the UN Framework Convention on Climate Change. New York: United Nations; 1997.

3. Schlamadinger B, Bird N, Johns T, Brown S, Canadell J, Ciccarese L, et al. A synopsis of land use, land-use change and forestry (LULUCF) under the Kyoto Protocol and Marrakech Accords. Environmental Science \& Policy 2007;10(4):271-282. 
4. Schlamadinger B, Johns T, Ciccarese L, Braun M, Sato A, Senyaz A, et al. Options for including land use in a climate agreement post-2012: improving the Kyoto Protocol approach. Environmental Science \& Policy 2007;10(4):295-305.

5. Thomas S, Dargusch P, Harrison S, Herbohn J. Why are there so few afforestation and reforestation Clean Development Mechanism projects? Land Use Policy 2010;27(3):880-887.

6. Jindal R, Swallow B, Kerr J. Forestry-based carbon sequestration projects in Africa: Potential benefits and challenges. Natural Resources Forum 2008;32(2):116-130.

7. Streck C, Scholz SM. The role of forests in global climate change: whence we come and where we go. International Affairs 2006;82(5):861-879.

8. Timilsina GR, de Gouvello C, Thioye M, Dayo FB. Clean Development Mechanism potential and challenges in Sub-Saharan Africa. Mitigation and Adaptation Strategies for Global Change 2010;15(1):93-111.

9. Boyd E, Gutierrez M, Chang MY. Small-scale forest carbon projects: Adapting CDM to low-income communities. Global Environmental Change-Human and Policy Dimensions 2007;17(2):250-259.

10. Olsen K. The clean development mechanism's contribution to sustainable development: a review of the literature. Climatic Change 2007;84(1):59-73.

11. Paulsson E. A review of the CDM literature: from fine-tuning to critical scrutiny? International Environmental Agreements-Politics Law and Economics 2009;9(1):63-80.

12. Zomer RJ, Trabucco A, Bossio DA, Verchot LV. Climate change mitigation: A spatial analysis of global land suitability for clean development mechanism afforestation and reforestation.

Agriculture Ecosystems \& Environment 2008;126(1-2):67-80.

13. Smith J, Scherr SJ. Capturing the value of forest carbon for local livelihoods. World Development 2003;31(12):2143-2160.

14. Unruh JD. Carbon sequestration in Africa: The land tenure problem. Global Environmental Change-Human And Policy Dimensions 2008;18(4):700-707.

15. Figueres $C$. Policies and programs under the CDM, Sectoral CDM: Opening the CDM to the yet unrealized goal of sustainable development. McGill International Journal of Sustainable Development Law and Policy 2006;2(5):5-26.

16. Brown K, Adger N, Boyd E, Corbera-Elizalde E, Shackley S. How do CDM projects contribute to sustainable development? Tyndall Centre for Climate Change Research; 2004.

17. McCully P, Athanasiou T. Bad Deal for the Planet: Why Carbon Offsets Aren't Working and How to Create a Fair Global Climate Accord. Berkeley: International Rivers; 2008.

18. Bullock S, Childs M, Pickens T. A Dangerous Distraction: Why Offsetting is Failing the CLimate and People. London: Friends of the Earth (FoE); 2009.

19. Tschakert P, Coomes OT, Potvin C. Indigenous livelihoods, slash-and-burn agriculture, and carbon stocks in Eastern Panama. Ecological Economics 2007;60(4):807-820.

20. Brown K, Corbera E. Exploring equity and sustainable development in the new carbon economy. Climate Policy 2003;3:S41-S56.

21. Gundimeda H. How 'sustainable' is the 'sustainable development objective' of CDM in developing countries like India? Forest Policy and Economics 2004;6(3-4):329-343.

22. Nelson KC, de Jong BHJ. Making global initiatives local realities: carbon mitigation projects in Chiapas, Mexico. Global Environmental Change-Human and Policy Dimensions 2003;13(1):19-30.

23. Fennhan J. UNEP Risoe CDM/JI Pipeline Analysis and Database, May 1st 2010. 2010 [cited 2010 May]; Available from: http://cdmpipeline.org/

24. Boyd E, May P, Chang M, Veiga FC. Exploring socioeconomic impacts of forest based mitigation projects: Lessons from Brazil and Bolivia. Environmental Science \& Policy 2007;10(5):419-433.

25. Coomes OT, Grimard F, Potvin C, Sima P. The fate of the tropical forest: Carbon or cattle? Ecological Economics 2008;65(2):207-212.

26. Bozmoski AS, Hultman NE. Participant Perceptions of Risk and Benefit in Carbon Forestry: Evidence From Central Tanzania. The Journal of Environment Development 2010;19(1):4-27. 
27. Tschakert $P$. The costs of soil carbon sequestration: an economic analysis for small-scale farming systems in Senegal. Agricultural Systems 2004;81(3):227-253.

28. Boyd E, Hultman N, Roberts JT, Corbera E, Cole J, Bozmoski A, et al. Reforming the CDM for sustainable development: lessons learned and policy futures. Environmental Science \& Policy 2009;12(7):820-831.

29. Gong Y, Bull G, Baylis K. Participation in the world's first clean development mechanism forest project: The role of property rights, social capital and contractual rules. Ecological Economics 2010;69(6):1292-1302.

30. UNEP. UNEP Risoe CDM/JI Pipeline Analysis and Database, May 1st 2010. 2010 [cited 2010 May]; Available from: http://cdmpipeline.org/

31. Schneider $\mathrm{L}$. Is the CDM fulfilling its environmental and sustainable development objectives? Berlin, Germany: WWF; 2007.

32. Madlener R, Robledo C, Muys B, Freja J. A Sustainability Framework for Enhancing the Long-Term Success of Lulucf Projects. Climatic Change 2006;75(1):241-271.

33. Ellis F. Rural livelihoods and diversity in developing countries. Oxford; New York: Oxford University Press; 2000.

34. Bebbington A. Capitals and capabilities: A framework for analyzing peasant viability, rural livelihoods and poverty. World Development 1999;27(12):2021-2044.

35. Biernacki P, Waldorf D. Snowball Sampling - Problems and Techniques of Chain Referral Sampling. Sociological Methods \& Research 1981;10(2):141-163.

36. Corbera E, Brown K. Building Institutions to Trade Ecosystem Services: Marketing Forest Carbon in Mexico. World Development 2008;36(10):1956-1979.

37. Tamale E, Jones N, Pswarayi-Riddihough I, World Bank. Technologies related to participatory forestry in tropical and subtropical countries. Washington, D.C.: World Bank; 1995.

38. UNFCCC. UNFCCC Clean Development Mechanism (CDM) Rulebook. 2010 [cited 10 May 2010; Available from: http://cdm.unfccc.int]

39. Ginoga K, Wulan YC, Djaenudin D. Potential of Indonesian Smallholder Agroforestry in the CDM: A Case Study in the Upper Citanduy Watershed Area. Bogor, Indonesia: ICRAF; 2004.

40. CCBA. Project Design Document for Project Activities. 2008 [cited 2010 May 10]; Available from: http://www.climate-standards.org/projects/index.html

41. Grieg-Gran M, Porras I, Wunder S. How can market mechanisms for forest environmental services help the poor? Preliminary lessons from Latin America. World Development 2005;33(9):1511-1527.

42. Trabucco A, Zomer RJ, Bossio DA, van Straaten O, Verchot LV. Climate change mitigation through afforestation/reforestation: A global analysis of hydrologic impacts with four case studies. Agriculture Ecosystems \& Environment 2008;126(1-2):81-97.

43. Sutter C, Parreno JC. Does the current Clean Development Mechanism (CDM) deliver its sustainable development claim? An analysis of officially registered CDM projects. Climatic Change 2007;84(1):75-90.

44. Hall R, Finch S, Lovera S, Sikking Y. Life as Commerce: the impact of market-based conservation on indigenous peoples, local communities, and women: Global Forest Coalition, CENSAT Agua Viva, COECOCEIBA, EQUATIONS, Alter Vida, the Timberwatch Coalition; 2008.

45. Sudha P, Ramprasad V, Nagendra M, Kulkarni H, Ravindranath N. Development of an agroforestry carbon sequestration project in Khammam district, India. Mitigation and Adaptation Strategies for Global Change 2007;12(6):1131-1152.

46. Landell-Mills N, Porras I. Silver bullet or fool's gold? A global review of markets for forest environmental services and their impacts on the poor. London: International Institute for Environment and Development; 2002.

47. May P, Boyd E, Veiga F, Chang M. Local sustainable development effects of forest carbon p rojects in Brazil and Bolivia. London: International Institute for Environment and Development; 2004. 
48. Asquith NM, Vargas Ríos MT, Smith J. Can Forest-protection carbon projects improve rural livelihoods? Analysis of the Noel Kempff Mercado climate action project, Bolivia. Mitigation and Adaptation Strategies for Global Change 2002;7(4):323-337.

49. Jindal R, Kerr J, Nagar S. Voluntarty Carbon Trading: potential for community forestry projects in India. Asia-Pacific Development Journal 2007;14(2):107-126.

50. UNFCCC. Project Design Documentation (PDD). 2010 [cited 2010 May 10]; Available from: http:// cdm.unfccc.int/Projects/index.html

51. Ringius L. Soil carbon sequestration and the CDM: Opportunities and challenges for Africa. Climatic Change 2002;54(4):471-495.

52. UNFCCC. Report of the Conference of the Parties serving as the meeting of the Parties to the Kyoto Protocol on its first session, held at Montreal from 28 November to 10 December 2005. New York: United Nations; 2006. 